\title{
A Meta-Modeling of User and the Development of Human and Intellectual Capital
}

\author{
Sidi Mahmoud Aidara Mbibi, Balla Diop and Daniel Pascot \\ Centre de Recherche et de Transfert en Architecture d'Entreprise (CeRTAE), Department of \\ Organizational Information Systems, Faculty of Business Administration (Laval University)
}

\begin{abstract}
The concept of user of organizational information system (OIS), contrary to the general thinking among both practitioners and researchers, is problematic. This work therefore seeks to set this concept by referring to literature in OIS. The authors have proposed a theoretical framework that models the different dimensions to consider when determining the different user profiles in an introduction of an IS/IT. The finding of this work is, in particular, a metamodel of the user operating in an environment where the information system is considered as a set of social actors that store and process information-representations through technological artefacts of information. Each type of user has a specific role or involvement in an IS / IT project. Exchanges and interactions, during the project, allow each type of user to contribute to the development of the stock of intellectual resources (knowledge, skills, competence, etc.) which increases the level of human capital and intellectual capital.
\end{abstract}

Keywords: User, meta-model, information system, human and intellectual capital.

\section{Introduction}

The concept of user in Organisational Information System (OIS), contrary to the general thinking among both practitioners and the researchers, generates problem in the sense where we distinguish several types of users : human user (an individual who uses the system within the framework of its leisure time); the professional user (an individual who uses the system within the framework of its community activities), the user designer (the person responsible for designing and eventually to conceive or develop the system). Moreover, another typology of the user is that which consists of distinguishing the user in the context of single-user systems (a system which is accessible by a single user - within the meaning of the human user and of the professional user) and the user in the context of the multi-user systems (a system who is accessible by multiple users simultaneously (i.e. the case of the computing systems deployed in the network) or not (i.e. the case of the automatic tellers of machines). Among the professional users, it is also important to determine the difference between the decision-makers within the organization and the users in operational level. Therefore, it is capital to carry a critical glance on the concept of user in OIS. User is he just an actor looking for information in a concert of networks (Doolin and Lower, 2002) in order to strengthen its authority or a social actor "whose everyday interactions are infused with information and communication technologies (ICT) 》 (Lamb and Kling, 2003: 197) or an individual endowed with common sense and making use of discourse analysis (Olsson, 2009) to better operate in its environment or finally, the user is it this individual who can change his intention to use a system in phase of postimplementation (Elbanna, 2010)? Can one work out a cognitive map expressing the «meta-model » of the concept of user in OIS? This document is a theoretical research to try to answer these questions. In what follows, we will first talk about the

Copyright (C) 2012 Sidi Mahmoud Aidara Mbibi, Balla Diop and Daniel Pascot. This is an open access article distributed under the Creative Commons Attribution License unported 3.0, which permits unrestricted use, distribution, and reproduction in any medium, provided that original work is properly cited. Contact author: Sidi Mahmoud AidaraMbibi E-mail: sidi-mahmoud-aidara.mbibi@fsa.ulaval.ca 
evolution of SI and the role of IS users. Then we will try to make a synthesis and integration the work of Doolin and Lower (2002), Lamb and Kling (2003), Olsson (2009) and Elbanna (2010) in order to define the concept of user in OIS. This will involve trying to understand the key dimensions to better define the concept of user. Once the notion of user clarified in terms of its dimensions, we will try to propose a cognitive map expressing a meta-model of the user operating in its environment. This meta-modeling is a good basis for future research concerning the development of human capital and intellectual in the context of IS / IT such as enterprise system. Then, the meta-model proposed will be explained using a critical approach. We will finish by a conclusion which will attempt to make a synthesis of carried out work and contributions.

\section{Evolution of IS and the Role of Users}

To compete effectively in their new business environment becoming increasingly globalized, enterprises, both small and medium enterprises (SMEs) that large firms, should adopt and use the IS/ITin order to support the continuous improvement of business processes. Some researchers raise the need for integrating all the IS/IT while others point to the importance and urgency to streamline and standardize workflows, data integration, organizational business processes. All of this will help enterprises to increase their productivity and to improve their customer service in their very difficult competitive environment. Information Systems have considerably changed over the past few years from silo systems to integrated systems (like enterprise systems). The implementation of integrated systems is both complicated and difficult because the product spans functional silos and involves many internal and external entities.

Swanson (1994) proposes a typology categorizing IS/IT based on their degree of difficulty or complexity during their implementation: type I, type II to type III. Among the technological innovations of type III, there are several sub-categories such as the type IIIa, IIIb and IIIc (Swanson, 1994). IS/IT of type IIIc are the most complex software applications to implement and to manage their evolution like management of upgrading and maintenance activities. The development and implementation of IS/IT of type IIIc, as any application of type III, generally requires enormous talent, skills and knowledge. The adoption of IS/IT within an organization is often considered like the introduction of technological innovation. Beyond this classification of IS/IT applications, the role and involvement of users in the implementation of IS/IT have evolved and vary depending the complexity of the application to be implemented, in other words, depending on the type of project IS/IT.

In an application development project of IS/IT internally, i.e. projects of type I (Swanson, 1994), the role of the end users in the project is reduced to a passive role of functional expert. However, in an implementation project of type III system (particularly systems of type IIIc (Swanson, 1994) as projects of enterprise system such as projects of implantation of Customer Relationship Management systems (CRM), Supply Chain Management systems (SCM), Enterprise Resource Planning (ERP)), end users play an active role of functional expert (Soh et al., 2000; Dong-Gil et al., 2005).In projects of implementation of enterprise systems, users play an important role in the development of knowledge and technical skills system. Note that this knowledge and these skills are a part of organizational human capital. In the literature of the information system, several studies have been made in the field of adoption and diffusion of IS/IT within organizations particularly studies concerning factors of acceptance or rejection of IS/IT by users. Different theoretical models have emerged to understand the user behavior during the adoption or diffusion of IS/IT within organizations: the theory of innovation diffusion, theory of planned behavior (TPB),technology acceptance model (TAM), theory of reasoned action (TRA) motivational model (MM); theory of Planned Behavior (TPB) and combined TAM and TPB (C-TAM-TPB), Triandis model, etc. All these theoretical models are 
based, generally, around the user's behavior at the adoption of IS/IT. These theories are being studied, in fact, the different facets of the user (like cognitive, social, psychological and organizational dimension, etc.) that could impact on the adoption behavior of the IS/IT. The adoption behavior of IS/IT is measured in terms of the perception, motivations, intention, psychological state, social or organizational environment, training program, satisfaction of the user. In so ruling, we note that the user has an important place in the theories applied in research on SI adoption of new IS / IT.

By this observation, we see that the user has an important place in the theories used in research in the IS field concerning the adoption of new IS / IT. Despite the many theories and their use in research in IS, however, the failure rate of adoption of IS/IT systems, particularly in the case of enterprise systems projects, still remains high. Given this, it is necessary to refocus the efforts of research in IS/ IT in order to understand the concept of user in a holistic way. This research thus aims to grasp the concept of the user through a metamodeling cognitive map. The aim of this research is to grasp the concept of the user through a meta-modeling by cognitive map.

\section{Concept of User in Organizational Information System (OIS)}

Doolin and Low (2002) studied the concept of user computer system following an approach based on the sociological model of Callon (1991). The user may be seen in the context of work of Doolin and Low (2002) as an individual who seeks to reveal his own knowledge by a critical process in its search for information by means of the technology which is the computer system. Therefore, Doolin and Low (2002) conceive the user of the system from the perspective of the theory of Network-Actor proposed by Callon (1991). In this perspective, the user tries to represent its theoretical constructs relying on complex associations between human and non-human actors of the networks. By relating the example of geographic information systems, Doolin and Low (2002) seems to draw our attention to the influence of social, political and cultural context on users of the computer system. To Doolin and Low (2002), the ontological considerations are also important for the user in OIS. Indeed, the user operates a computer system to give meaning to the concepts which he handles. Lamb and Kling (2003) propose, in turn, to re-conceptualize the user in his environment by considering him as a social actor. By this definition of the user, these authors attempt to overcome the impasse created by the critics on the definition reducing the user as « an atomic individual with well articulated preferences and the ability to exercise discretion in ICT choice and use, within certain cognitive limits » (Lamb and Kling, 2003: 198). This very narrow definition of the user does not consider the multiple and complex roles of the information system user. Therefore, Lamb and Kling (2003) proposes to consider the user of information system (IS) as a « social actor characterized by four main dimensions: affiliations, environments, interactions, and identities » (Lamb and Kling, 2003, p. 204). Olsson (2009), for its part, makes a criticism on the notion of IS user, while relying on the theories of the good sense of Brenda Dervin and the analytical speech of Foucault. Considering the user as the focal point in a IS, it offers a holistic approach to understanding the complex relationships between people, information and their social context. Finally, Elbanna (2010), by a study of the failure of the effective use of an online shopping system whose users had a positive perception according to the Technology Acceptance Model (TAM), showed, inter alia, that the change of powers between users of a computer system could attenuate or even reverse the effect of the intention of use.

After having tried to position the concept of user of information system, we propose in the following a meta-model of this concept expressed by a cognitive map. 


\section{Meta-Modeling of the Concept of User with a Cognitive Map}

\section{Meta-Modeling and Cognitive Map}

Meta-modelling is an approach for defining modelling languages, in particular the Unified Modelling Language (UML), and involves the construction of an objectoriented model of the abstract syntax and, optionally, the concrete notation and semantics of the target language (Clark et al., 2003). Emphasis lies on meta-modelling as a technique for sensitivity analysis, and on experimental design as a tool for improving the efficiency and effectiveness of experiments with the model (Rotmans and Vrieze, 1999). The meta-modeling approach is becoming a standard way of defining and managing the meta-models that is used for designing the domainspecific models (Kim et al., 2006). In this paper, a meta-model is a collection of concepts that are related to define the IS/IT user and his/her expectations of the IS / IT. Each concept could be defined using a model. In this way, the meta-model is formalized as a cognitive map in the sense that a cognitive map is a depiction of the knowledge from one individual on a specific field (Tolman, 1948) and is a model of causal representation between concepts (Laukkanen , 1994).

\section{Bases of the Meta-Model}

The meta-model of figure 1 shows the relationship between the principal users and the information system (or technology) within an organization. In their work, Vidal and Petit (2009) made a literature review on the principal definitions of the information system. The absence of a consensual definition among the researchers shows polysemy surrounding the definition of the concept of information system. Based on the work of Simon (1947) and those of Rowe and Reix (2002), we define the information system as a set of social actors that store and process the information-representations via technological artefacts of information. This technological artefact, i.e. the information system or information technology (IS/IT), is not perceived in the same way by the different users in the organization. This artefact can be regarded as social construct that is governed by relations of communication, sharing, and reuse of information between users. Any user (decision-makers, system designer, end-user) is in continuous interaction with the IS/IT. In addition, this user is in continuous and ongoing interactions with other types of users in the organization through IS / IT. In this sense, Lamb and Kling qualify the user as being a social actor. The social aspect is seen through the key dimensions of the user of IS/TI (i.e. affiliations, environments, interactions, identities). So, this meta-model is based on the sense of criticism as proposed by Doolin and Lowe (2002) of the user in his process of search for information. It assumes that the IS/IT is a means which contributes to the development of the network socio-technique of Callon as criticized and enriched by Doolin and Lowe (2002). This network must be structuring, on the one hand, to give a good sense to the information that it permits to share and, secondly, to allow a critical analysis of this information by the user. As that was raised by Elbanna (2010), the risk to reject a system is not null even in phase of postimplementation. Therefore, this metamodel of the user assumes that the IS / IT must be able to manage and deal with new business processes of the organization and to maintain the power game between different users while allowing selective access to data.

\section{Description of the Meta-Model}

To better understand the concept of user, the meta-model is developed in the context of the introduction or diffusion of a new IS/IT within an organization. To this end, we can distinguish three profiles of users within an organization: (1) decisionsmakers (2) employees and (3) system designers. The first two profiles include the professional users whereas the third profile represents the systems designers as mentioned in introduction. Each user profile is an entity. The IS/IT is represented by three dimensions: positive perception of the IS/IT, the negative perception of the IS/IT and the use of the 
IS/IT (cf. figure 1). Each user profile has its own perception of IS/IT.

In general, the decision-makers and the systems designers have the same kind of utopian discourse with respect to the introduction and use of the IS/IT: they have a positive perception of IS / IT. For the decision-maker, the IS/IT is very crucial for an organization and is a viable tool for building a competitive advantage. In this sense, the IS/IT represents for the decision-maker a tool which must contribute to ensure an organisational effectiveness. Moreover, for the decisionmaker the IS/IT is an effective means of solving organizational problems.

From an organizational perspective, the system designer considers that the use of IS/IT is a means to ensure transparency and interoperability of the system with other systems in order to facilitate the sharing and communication of information within the organization.

Considering the tight control of IS/IT by the system designer, those see the technological artefacts like effective means of solving organizational problem. From the perspective of the system designer, the adoption or introduction of a IS/IT makes it possible to contribute to the organisational and personal owing to the fact that the IS/IT is supposed to help different organizational actors to perform their duties more effectively.

From the perspective of the employee, the IS/IT can be perceived positively or negatively. The positive perception is the degree to which the employee perceives the usefulness of the IS/IT in terms of expected return. When the employee perceives positively IS/IT, he is more willing to make efforts to adapt in order to gain a better expected return.

The employee can have a negative perception with regard to the IS/IT because of two factors: resistance to change and the categorical rejection/ refusal. The resistance to change may be due to two factors: (a) anxiety and fear of change and (b) the potential risks of loss of power.

About of the refusal / rejection of an employee with regard to the introduction of a IS/IT, this may be explained by the fear of loss of power of the employee or by socio-demographic factors (age, gender...). The IS/IT may also be refused categorically because of the degree of richness of information provided by the system.

At the organisational level where the social context and cultural of the user is important, the richness of information is defined by the common sense of the information provided and managed by the IS/IT as well as the conformity of information with respect to business rules.

The richness of information nourishes the positive perception of the actors with respect to the IS/IT.

From the usage perspective, the IS/IT represents effective means to solve organizational problems both for the employee, the decision-maker and system designer. The use of a good IS/IT may be seen by employee like a means of increasing his personal effectiveness within the organization in order to obtain a better periodic evaluations.

\section{Discussion}

In today's economy, the abilities to develop knowledge management as well as human and intellectual capital are essential for the success in almost any organization. At the same time, the evolving role of IS has resulted in the emergence and the mass adoption of applications of type III, i.e. complex IS such as enterprise systems (CRM, ERP, SCM, etc...).Therefore, the apprehension of the concept of user has become more necessary than ever in the IS field. The user is now an active functional expert in the complex IS projects implementation. To this end, during implementation of a complex IS / IT, the user interacts with other external stakeholders (consultant, integrator, etc...). This interactions result in the creation and 
sharing their knowledge and skills on IS / IT to implement.

These multiple interactions or exchanges are also increasing the level of intangibles capitals (i.e. the level of human and intellectual capital). With the changing role of the user, this one becomes a decisive actor in the development of these capitals that many researchers consider nowadays as the main resource upon which depend the organizational performance and growth. In fact, in this new digital age or immaterial, an increasing number of researchers advocate human and intellectual capital as the main organizational sources of competitive advantage (Cabrera and Cabrera, 2005; Nahapiet and Ghoshal, 1998). Intellectual capital of an organization is a function of the stock of knowledge accumulated by individuals and units (Gupta and Govindarajan, 2000). In the context of an IS/IT project, the intellectual capital can be defined as the stock of knowledge accumulated by individuals and units concerning the IS/IT artefact introduced. Regarding the human capital, Hayes (2003) perceives it as the best resource to grow any business. This is consistent with the works of Bontis (1998) who considers that human capital is, nowadays, significant for all organizations because it is a source of innovation and strategic renewal. Human capital refers to the know-how, skills, and capabilities of individuals in an organization (Lengnick-Hall and LengnickHall, 2006) concerning the IS/IT. Like physical and social capital, human capital can facilitate productive activity (Coleman, 1988). Human and intellectual capitals are crucial resources to the success of an organization (Cabrera and Cabrera, 2005; Nahapiet and Ghoshal, 1998; Lepak and Snell, 1999). According to these authors, each organization must develop its own human capital to support the development of its sustainable competitive advantage. In the context of implementation of an IS / IT, the human and intellectual capitals are affected by the role played by the user; therefore understanding the concept of user is more than ever an important topic in the field IS. The proposed meta-model of the user concept has revealed three profiles of users within an organization: (1) decisions-makers (2) employees and (3) system designers. During the implementation of a complex IS/IT, as an enterprise system, there are several types of knowledge and skills transferred: those relating to technical infrastructure, those relating to business processes and those relating to the project management (i.e. methodology and procedures). All these knowledge transferred increase the stock of intellectual resources such as the stock of knowledge, know-how and skills; in other words, the level of human and intellectual capital. Better representation of the user concept enables future research to have a good understanding of the complexity of the concept of user as well the different roles played by each of the three profiles of user in the development of human and intellectual capital during the adoption and the usage of an IS/IT. The degree of intervention or involvement of each of the three user profiles may vary depending on the type of IS/IT to be implanted. An IS/IT may be accepted by one of three user profiles while being rejected by other types of users. Thus, the use of IS/IT depends on the adoption of IS/IT. This adoption may vary from one type of user to another. Therefore, more an IS / IT is accepted and more its use is widespread allowing each type of user to contribute to the development of organizational human and intellectual capital. 


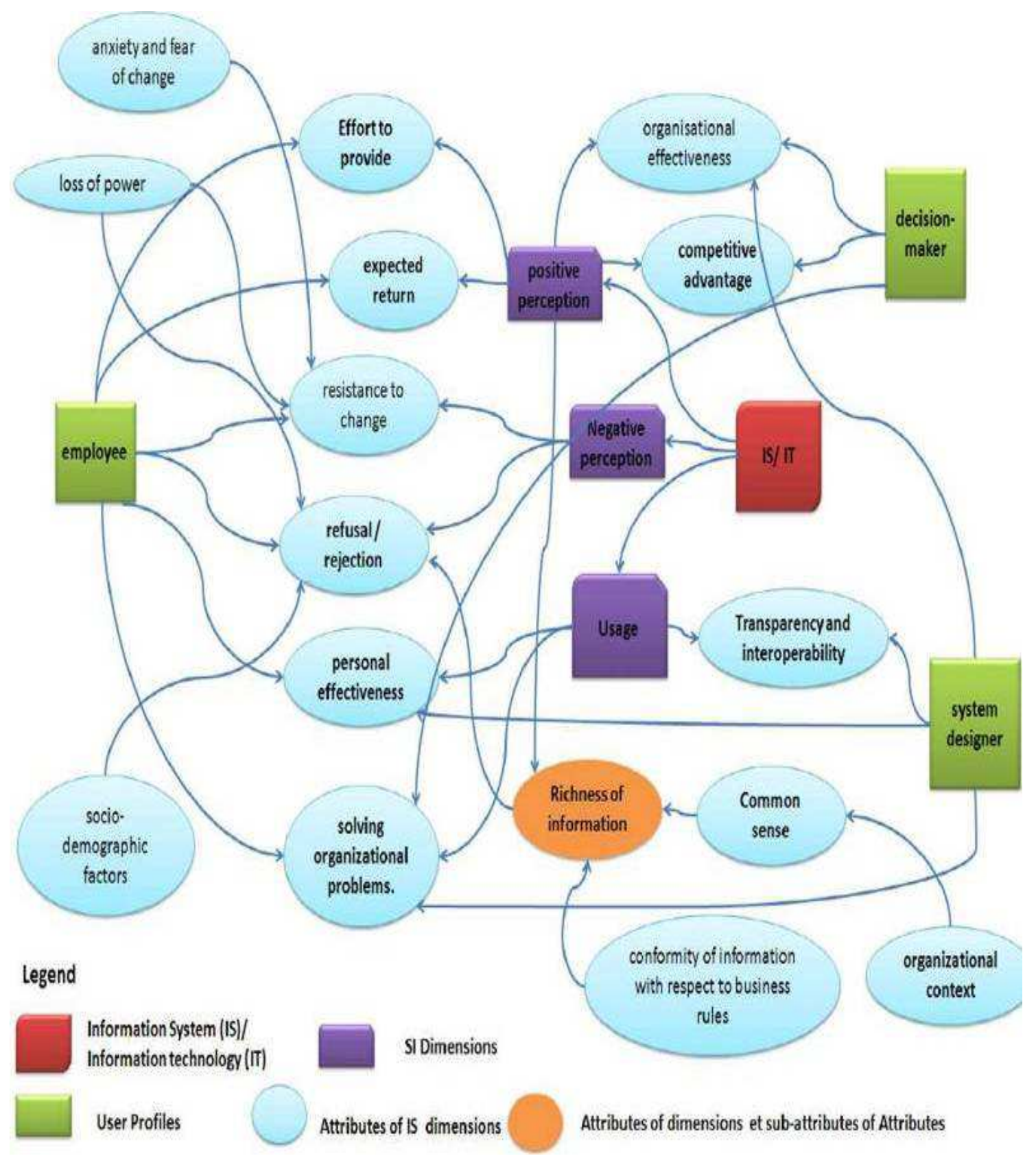

Fig. Meta-Model of the OIS User Expressed as a Cognitive Map 


\section{Conclusion}

The concept of user in OIS should be viewed or apprehended holistically. Instead of regarding it as an atomic individual, the user must be modeled using a multidimensional approach. Thus, it will be possible to propose an IS/TI allowing the user to satisfy his needs for searching information in his role of social actor. Effectively, the texts studied confirm the equivocal nature of "what is generally given to understand by the concept of IS/TI user. We recognize and acknowledge that there is indeed a "moose on the table" (Tobias, 2003) about the notion of user. That's why we also propose a meta-model of the IS/IT user based on Doolin and Lower (2002), Lamb and Kling (2003), Olsson (2009) and Elbanna (2010). However, this meta-model, although we have tried to prove its theoretical basis, must be circumscribed in an empirical context in order to test its validity and its ability to effectively capture the expectations of users in the implementation of a IS/TI. Over the years, several theories have emerged in order to better understand the behaviour of user, the effect or impact of the adoption or diffusion of IS/IT to users, the use of IS/TI within an organization. The user holds a central level research in the field of the OIS (Lee and Myers, 2004). Therefore, it is important to correctly identify the type of study of the user. Thus, this research contributes in several manners to the literature relating to the conceptualization of the OIS user. In particular, it allowed to propose a theoretical framework that models the different dimensions to be considered when determining the different user profiles as part of an introduction of an IS / IT. Furthermore, this research shows how a better understanding of the role of the user in OIS can contribute to the development of human and intellectual capital of the organization.

\section{References}

Bontis, N. (1998). "Intellectual Capital: An Exploratory Study That Develops Measures and Models," Management Decision, 36 (2): Pg. 63-76.
Cabrera, E. F. \& Cabrera, A. (2005). "Fostering Knowledge Sharing through People Management Practices," International Journal of Human Resource Management, 16 (5): Pg. 720-735.

Clark, T., Evans, A. \& Kent, S. (2003). "Aspect-Oriented Metamodelling," The Computer Journal, Vol. 46, (5); 566-577.

Coleman, J. S. (1988). "Social Capital in the Creation of Human Capital," The American Journal of Sociology, Vol. 94 (S1), Pg. S95S120.

Doolin, B. \& Lowe, A. (2002). "To Reveal Is to Critique: Actor-Network Theory and Critical Information Systems Research," Journal of Information Technology London, 17 (2), 69-78.

Elbanna, A. (2010). "From Intention to Use to Actual Rejection: The Journey of an EProcurement System," Journal of Enterprise Information Management, 23 (1), 81-99.

Gupta, A. K. \& Govindarajan, V. (2000). "Knowledge Management's Social Dimension: Lessons from Nucor Steel," Sloan Management Review, Vol. 42 (1), Pg. 71-80.

Hayes, M. (2003). "Niche Development Tips: CPAs with Strong Service Specialties Share Some Details About How to Make Them Grow," Journal of Accountancy, Vol. 196 (6), Pg. 45-54.

Kim, T.- Y., Lee, S., Kim, K. \& Kim, C.- H. (2006). "A Modeling Framework for Agile and Interoperable Virtual Enterprises," Computers In Industry, 57, 204-217.

Ko, D.- G., Kirsch, L. J. \& King, W. R. (2005). "Antecedents of Knowledge Transfer from Consultants to Clients in Enterprise System Implementations," MIS Quarterly, Vol. 29 (1), Pg. $59-85$.

Lamb, R. \& Kling, R. (2003). "Reconceptualising Users as Social Actors in Information Systems Research1," MIS Quarterly, 27 (2), 197-235. 
Laukkanen, M. (1994). "Comparative Cause Mapping of Organizational Cognitions," Organization Science, 5, 322-343.

Lee, J. C. \& Myers, D. M. (2004). "Dominant Actors, Political Agendas, and Strategic Shifts Over Time: A Critical Ethnography of an Enterprise Systems Implementation," The Journal of Strategic Information Systems, 13 (4), 355-374.

Lengnick-Hall, C. A. \& Lengnick-Hall, M. L. (2006). "HR, ERP and Knowledge for Competitive Advantage," Human Resource Management, Vol. 45 (2), Pg. 179-194.

Lepak, D. P. \& Snell, S. A. (1999). "The Human Resource Architecture: Toward a Theory of Human Capital Allocation and Development," Academy of Management Review, Vol. 24 (1), Pg. 31-48.

Nahapiet, J. \& Ghoshal, S. (1998). "Social Capital, Intellectual Capital, and the Organizational Advantage," The Academy of Management Review, Vol. 23 (2), Pg. 242266.

Olsson, M. R. (2009). "Re-Thinking Our Concept of Users," Australian Academic and Research Libraries, 40 (1), 22-35.

Rotmans, J. \& Vrieze, O. J. (1999). "Metamodelling and Experimental Design: The Greenhouse Effect," European Journal of Operational Research, 47, 317-329.

Rowe, F. (2002). Faire de la Recherche en Systèmes d'information, Vuibert, CEFAG.

Simon, H. A. (1947). Administrative Behavior, Macmillan, New York, NY.

Soh, C., Kien, S. S. \& Tay-Yap, J. (2000). "Cultural Fits and Misfits: Is ERP a Universal Solution?," Communications of the ACM, Vol. 43 (4), Pg. 47-51.

Swanson, E. B. (1994). "Information System Innovation among Organizations," Management Science, Vol. 40 (9), Pg. 10691092.
Tobias, R. \& Tobias, T. (2003). Put the Moose on the Table: Lessons in Leadership from a CEO's Journey through Business and Life, Indiana University Press, Bloomington, IN.

Tolman, E. C. (1948). "Cognitive Maps in Rats and Men," Psychological Review, 55 (4): 189-208.

Vidal, P. \& Petit, V. (2009). Systèmes d'information Organisationnels / [Collaborateurs] François Lacroux Marc Augier Valéry Merminod. - Pearson Education. 